\title{
Impact of appetitive and aversive outcomes on brain responses: linking the animal and human literatures
}

\author{
Gregory B. Bissonette*, Ronny N. Gentry, Srikanth Padmala, Luiz Pessoa and Matthew R. Roesch
}

Department of Psychology, University of Maryland, College Park, MD, USA

Edited by:

Dave J. Hayes, University of Toronto,

Canada

Reviewed by:

John D. Salamone, University of

Connecticut, USA

Thilo Womelsdorf, Robarts Research

Institute London, Canada

*Correspondence:

Gregory B. Bissonette, Department of

Psychology, University of Maryland,

1148 Biology-Psychology Building,

College Park, MD 20742, USA

e-mail: bissonette@gmail.com

\begin{abstract}
Decision-making is motivated by the possibility of obtaining reward and/or avoiding punishment. Though many have investigated behavior associated with appetitive or aversive outcomes, few have examined behaviors that rely on both. Fewer still have addressed questions related to how anticipated appetitive and aversive outcomes interact to alter neural signals related to expected value, motivation, and salience. Here we review recent rodent, monkey, and human research that address these issues. Further development of this area will be fundamental to understanding the etiology behind human psychiatric diseases and cultivating more effective treatments.
\end{abstract}

Keywords: reward processing, salience, value encoding, appetitive and aversive outcomes, neural encoding

\section{INTRODUCTION}

Decision making is a complex process by which an organism must weigh multiple possible outcomes against current and long term goals before deciding on a course of action. Possible outcomes can be grouped into the probability of obtaining something rewarding or avoiding an outcome that is negative or punishing. Although an established body of literature has extensively studied neural systems involved in both of these functions, very few have set out to explicitly study how these neural systems directly reconcile both appetitive and aversive neural signals in a single task. Even fewer have addressed questions related to how anticipated appetitive and aversive outcomes interact to alter neural signals related to expected value, motivation, and salience. Here, we review studies that have addressed this issue in a number of key brain areas, all of which have been shown to exhibit neural activity modulated by expectation of appetitive and aversive stimuli when studied independently. We first review the non-human animal literature and then review studies performed in humans.

We know from a vast literature that neural activity of several regions throughout the brain are modulated by expected outcome, whether it be appetitive or aversive. It is widely assumed that this activity corresponds to an internal representation of how appetitive or aversive that expected outcome is. However, in many cases, change in responses relating to the expectation of emotionally charged outcomes alters other functions related to motivation, salience, arousal and attention that serve to facilitate response mechanisms to approach or avoid.

For example, an association of a particular odor that previously predicted the presence of a predator would be highly salient though lead to a negative association with that odor, while another odor may predict a salient rewarding stimulus, like ripe fruit, but with a positive valence. So while the general idea that appetitive and aversive systems oppose each other in the brain seems logical and useful (Solomon and Corbit, 1974; Daw et al., 2002), stimuli of either valence may drive arousal or enhance attention to stimuli of learned associations (Anderson, 2005; Lang and Davis, 2006; Phelps et al., 2006; Anderson et al., 2011).

Thus, a key problem is how to dissociate value from these other co-varying factors. A common approach is to vary appetitive and aversive stimuli in the same task. In these types of studies there are typically three basic trial types, such that: (1) a conditioned stimulus (CS) predicts a large reward; (2) a CS predicts a neutral condition or a small (or no) reward; and (3) a CS predicts a small (or no) reward with the threat of an aversive outcome. In animal studies, the aversive outcome may range in quality from time-outs, delivery of a bitter quinine solution, electric shock, or air-puff to the eye (Rolls et al., 1989; Roesch and Olson, 2004; Anstrom et al., 2009; Brischoux et al., 2009; Matsumoto and Hikosaka, 2009; Roesch et al., 2010a; Lammel et al., 2011; Bissonette et al., 2013). In human studies, the aversive outcome may be loss of money, an unpleasant liquid, shock, or an unpleasant odor (Delgado et al., 2000; Anderson et al., 2003; Small et al., 2003; Cooper and Knutson, 2008; Carter et al., 2009; Litt et al., 2011; Choi et al., 2013). If neurons encode value, activity should show a decreasing relationship during appetitive, neutral, and aversive trials (Figure 1). If appetitive and aversive stimuli are encoded by independent populations, then neurons should be modulated by either appetitive or aversive stimuli but not both. Finally, if activity is modulated by factors that vary with the strength of appetitive and aversive stimuli, neurons should respond with the same "sign" for appetitive and aversive trials compared to neutral trials (Figure 1). Although the relationship between neuronal responses and blood-oxygenationrelated activity obtained via functional MRI is complex (Goense and Logothetis, 2008), it is typically assumed that the same 


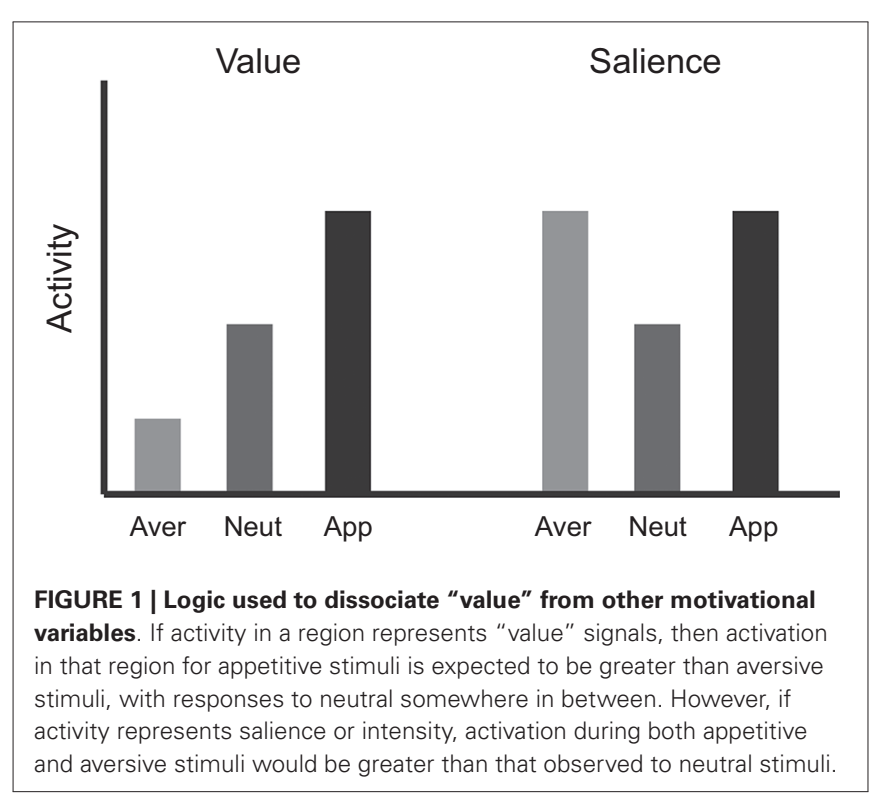

pattern of activity applies to them both-thus, the same type of relationships should be observed at the levels of voxels or regions.

Below we first focus on animal studies that have used similar paradigms to try to dissociate value from motivation, salience, arousal and intensity. We then turn to functional MRI studies in humans.

\section{ORBITOFRONTAL CORTEX (OFC)}

Orbitofrontal cortex (OFC) encodes expectations about future appetitive and aversive outcomes that are critical for guiding learning and decision-making (Schoenbaum et al., 1998; Roesch and Olson, 2004; Schoenbaum and Roesch, 2005; Plassmann et al., 2010; Morrison et al., 2011; Morrison and Salzman, 2011). For example, neurons in OFC are modulated by cues that predict different appetitive outcomes, such as different food stuffs and magnitudes of reward; other OFC neurons signal when an aversive stimulus is anticipated, such as quinine or airpuff. However, since motivation and value were hard to disentangle in most of these experiments, it was unknown whether neural signals genuinely represented the value of the predicted outcome, or the motivational level associated with obtaining reward or avoiding aversive outcomes. For example, neurons in OFC fire strongly when monkeys anticipate a desirable outcome (Schoenbaum et al., 1998, 1999), but if that outcome is paired with a chance for another, more preferable outcome (Wallis and Miller, 2003), or is devalued through satiation (Rolls et al., 1989), then the rate of firing decreases. This activity modulation might reflect the decrease in value, but it might also reflect changes in motivation. A similar situation holds true for OFC neurons that predict aversive outcomes; activity might reflect how aversive the stimulus is or how motivated the animal is to avoid it.

To address these issues Roesch and Olson (2004) designed a task to dissociate value from motivation by simultaneously manipulating reward and punishment. The monkeys performed a memory-guided saccade task during which two cues presented at the beginning of each trial indicated the size of the reward the monkey would receive in the event of success (one or three drops of juice) and the size of a penalty that would be incurred in the event of failure (a $1 \mathrm{~s}$ or $8 \mathrm{~s}$ timeout). Behavioral measures indicated that the monkeys found the large reward appetitive and the punishment aversive; monkeys chose a large reward more often than a small one and avoided a large penalty more often than a small one. More importantly, monkeys were more motivated by large rewards and penalties as compared to smaller ones. Under both the largereward and large-penalty conditions, the monkeys broke fixation less often, made fewer errors, and were faster to respond, relative to neutral conditions (Figure 2A). Thus dissociation of value and motivation was achieved via simultaneous manipulation of appetitive and aversive outcomes (Roesch and Olson, 2004).

With this task it was predicted that neurons sensitive to the degree of motivation should respond with similar changes in firing rate to increasing the size of either the promised reward or the threatened penalty, thus paralleling the behavior. Indeed, premotor (PM) neurons that are strongly associated with motor output fired continuously during the delay between predictive cues and the behavioral response at a higher rate when either a large reward or a large penalty was expected (Figures 2D, E). Since activity persisted throughout the delay into the time when the monkey was making the behavioral response and because enhancement was observed in neurons with response direction selectivity, changes in firing were interpreted as reflecting motivational enhancement of motor output, as opposed to general arousal or salience. Accordingly, activity in PM reflected the motivational impact of the trial being performed, not its overall value, demonstrating a dissociation between motivation from value at the neural level.

Since OFC is more associated with more emotional/evaluative functions than motor areas, like PM, we expected that OFC neurons would better reflect the value associated with cues and reward delivery. Indeed, in stark contrast to PM neurons, OFC neurons fired most strongly for cues that predicted large reward (with small penalty) and least strongly for cues that predicted large-penalty (with small reward) relative to neutral conditions (small reward and small penalty; Figures $2 \mathrm{~B}-\mathrm{C}$ ). Thus the strength of responding in OFC reflected the value conveyed by the combination of reward and penalty cues. Other studies have replicated these results and have further shown that other populations of OFC neurons do not represent the overall value associated with a given situation, but the actual offers being made and the option eventually chosen during performance of a choice task (Padoa-Schioppa and Assad, 2006, 2008; Hosokawa et al., 2007; Morrison et al., 2011). Collectively these studies have shown that OFC has all the signals necessary, at the single unit level, to make reward-guided decisions, as opposed to facilitating behavior through general motivational mechanisms under the influence of predictive appetitive and aversive events. 


\section{BASOLATERAL AMYGDALA (ABL)}

Although the mainstream view holds that amygdala is important for acquiring and storing associative information related to both appetitive and aversive outcomes (LeDoux, 2000), there have been hints in the literature that amygdala also supports other functions related to associative learning, such as signaling of attention, uncertainty, and intensity (Saddoris et al., 2005; Belova et al., 2007; Tye and Janak, 2007; Tye et al., 2010; Morrison et al., 2011).

At the single neuron level, basolateral amygdala (ABL) is modulated by the predictability of both appetitive and aversive events, specifically when expectancies are violated (Belova et al., 2007; Roesch et al., 2010a,b; Tye et al., 2010). In other words, ABL neurons increase firing when outcomes are unexpectedly delivered or omitted, events that are highly salient and attention grabbing. We have shown that activity in ABL increases when rewards are unexpectedly delivered (appetitive) or omitted (aversive) in a task in which expected reward varies in size and time to delivery (Roesch et al., 2010a). Others have reported increased activity in $\mathrm{ABL}$ when rats were expecting reward, but not delivered during extinction (Tye et al., 2010). In primates, unexpected delivery of appetitive and aversive (airpuff) outcomes during performance of a trace conditioning task with reversals caused amygdala neurons to fire more strongly than when the outcome was totally predictable (Belova et al., 2007). Additionally, it appears that the same populations of ABL neurons which represent appetitive stimuli were also activated by aversive stimuli, regardless of the particular sensory modality from which the experience comes (Shabel and Janak, 2009). This suggests a larger role for ABL in signaling the need for attention in the presence of cues, rather than signaling the associated value of those cues. All of this suggests that amygdala does more than just signal appetitive and aversive stimuli.

Together, these reports suggest that ABL integrates information about appetitive and aversive events and their intensity or salience, possibly in the service of modifying behavior via signaling errors in predictions or recruitment of attentional/executive functions. However, these reports tend to focus on modulation of activity during delivery of appetitive and aversive outcomes. Much less is known about modulation by salience during sampling of cues that predict outcomes. Notably, modulation of amygdala firing for cues that predict appetitive and aversive outcomes appears to occur in separate neurons, suggesting that activity during this period is more related to the valence of the expected outcome. Likewise, cues presented after unexpected events or during response conflict when enhanced attention is necessary do not elicit changes in activity as do errors in reward prediction or commission as observed in other areas, such as anterior cingulate. Thus, ABL might be critical for reporting attentional need, arousal or intensity during sampling of unconditioned stimuli in the service of learning to predict the appetitive and aversive nature of the outcomes during sampling of conditioned stimuli. This is consistent with the finding that $\mathrm{ABL}$ interference disrupts development of cue selectivity in other areas, such as OFC and ventral striatum (VS; Hatfield et al., 1996; Schoenbaum et al., 2003a,b; Stalnaker et al., 2007, 2009).

\section{VENTRAL STRIATUM (VS)}

The connectivity of VS with OFC and ABL suggests that it might also represent the value of expected outcomes. This would be consistent with its proposed role as the "critic" in actor-critic models, where VS generates value predictions about future outcomes, which are used by dopamine (DA) neurons to compute prediction errors (PEs) necessary for updating actions polices in the "actor", namely dorsal striatum (Houk et al., 1995; Sutton, 1998; Haber et al., 2000; Joel et al., 2002; Redish, 2004; Ikemoto, 2007; Niv and Schoenbaum, 2008; Takahashi et al., 2008; PadoaSchioppa, 2011; van der Meer and Redish, 2011). However, VS has traditionally been thought to be the "limbic-motor" interface critical for motivating behaviors. Under this framework, one might predict that VS is critical for motivating or facilitating behaviors in response to both appetitive and aversive stimuliand not for representing value per se. Consistent with both of these theories, pharmacological manipulations of VS impact motivated behaviors dependent on value expectations during a variety of tasks (Wadenberg et al., 1990; Berridge and Robinson, 1998; Blokland, 1998; Ikemoto and Panksepp, 1999; Di Ciano et al., 2001; Cardinal et al., 2002a,b; Di Chiara, 2002; Salamone and Correa, 2002; Giertler et al., 2003; Wakabayashi et al., 2004; Yun et al., 2004; Floresco et al., 2008; Gruber et al., 2009; GhodsSharifi and Floresco, 2010; Stopper and Floresco, 2011), including reward seeking (Ikemoto and Panksepp, 1999), cost-benefit analysis (Floresco et al., 2008; Stopper and Floresco, 2011), and delay/effort discounting (Cardinal et al., 2001; Ghods-Sharifi and Floresco, 2010).

Motivation is a complex psychological feature, likely arising from assessments of physiological states, understanding and attending to current environmental cues, past reinforcement history, and assessing expected value associated with current contexts. In this light, pharmacological manipulations of the VS will only likely uncover a portion of the story, while single unit recording may uncover separate yet concurrent roles for a brain region, difficult to piece apart with pharmacological work.

Previous single unit work has clearly demonstrated that firing in VS is modulated by the value associated with cues that predict reward in rats (Carelli and Deadwyler, 1994; Setlow et al., 2003; Janak et al., 2004; Nicola et al., 2004; Ito and Doya, 2009; van der Meer and Redish, 2009; Kalenscher et al., 2010; Lansink et al., 2010; van der Meer et al., 2010; Day et al., 2011; Goldstein et al., 2012) and monkeys (Schultz et al., 1992; Shidara and Richmond, 2004; Cromwell et al., 2005; Kim et al., 2009; Nakamura et al., 2012) performing a variety of instrumental tasks, including go/nogo (Schultz et al., 1992; Setlow et al., 2003), lever pressing (Carelli and Deadwyler, 1994; Janak et al., 2004; Shidara and Richmond, 2004; Cromwell et al., 2005; Day et al., 2011), discrimination (Nicola et al., 2004; van der Meer et al., 2010; Goldstein et al., 2012), maze running (van der Meer and Redish, 2009; Kalenscher et al., 2010; Lansink et al., 2010), and eye movement paradigms (Kim et al., 2009; Nakamura et al., 2012). However, from these studies, it was unclear what exactly VS responses represented because none of these studies had independently manipulated value from motivation. To address this issue we 


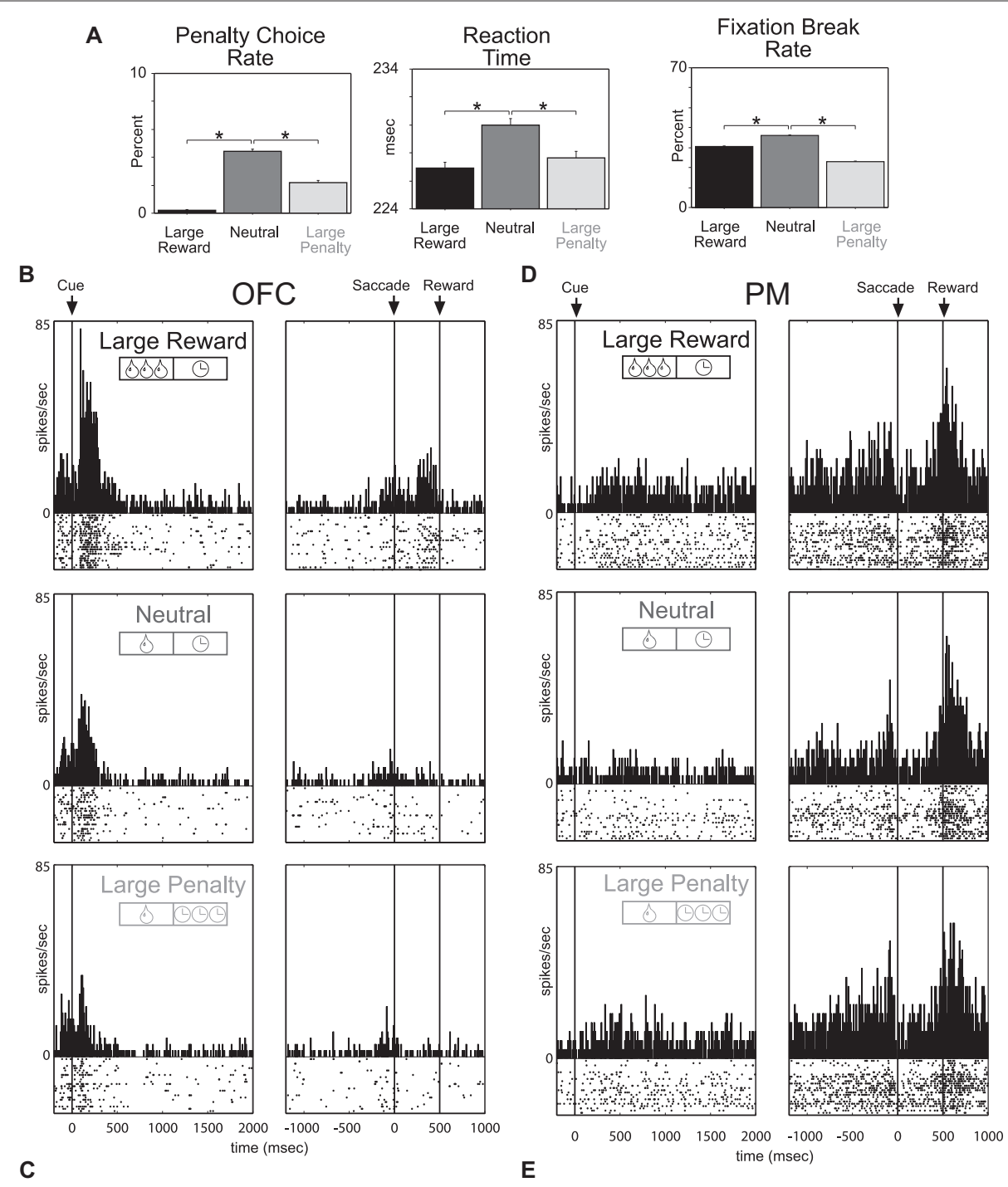

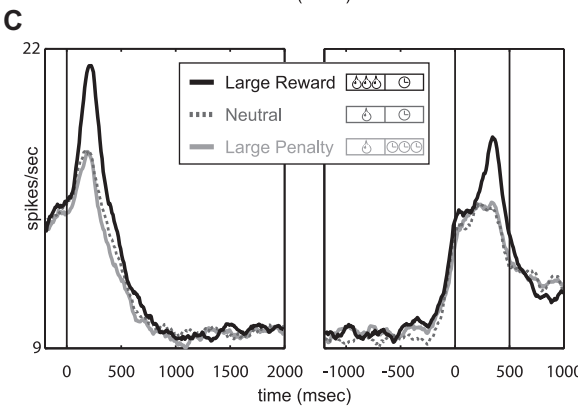

FIGURE 2 | Premotor and Orbitofrontal cortex encode motivation and value, respectively. Trials fell into three categories defined by

reward-penalty combination: large reward (large reward and small penalty), neutral (small reward and small penalty), and large penalty (small reward and large penalty). (A) Performance measures sensitive to reward and penalty size. Penalty choice rate: trials on which the monkeys chose penalty expressed as a fraction of all trials on which they chose reward or penalty. Fixation break rate: trials terminated by a fixation break expressed as a percentage of all trials. Reaction time: average interval between fixation spot offset and saccade initiation on all trials in which the monkey made a saccade in the rewarded direction. Asterisks (all planned
E

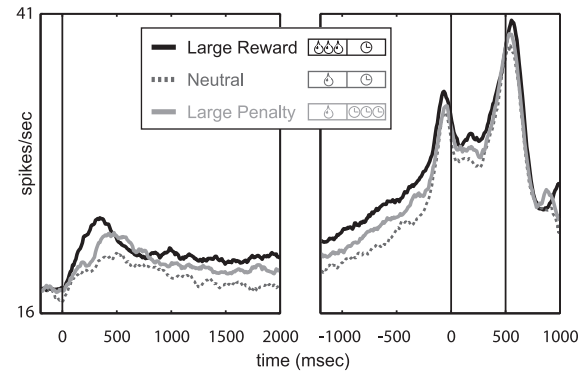

comparisons): statistically significant differences at $P<0.001$. (B, C) Neuronal activity in OFC reflects the value conveyed by the incentive cues. (B) Shown are data from a single neuron firing during the cue period at a rate that was especially high for large reward and especially low for large penalty. (C) Mean firing rate as a function of time under the three incentive conditions for all 176 OFC neurons. (D, E) Neuronal activity in premotor (PM) reflects the motivational impact of the incentive cues. (D) Shown are data from a single neuron firing throughout the trial at a rate that was high for large reward and large penalty. (E) Mean firing rate as a function of time under the three incentive conditions for all 135 PM neurons. Adapted from Roesch and Olson (2004). 
adopted a similar behavioral strategy in rats as we did in primates, varying expected reward and punishment so that value and motivation signals could be dissociated (Bissonette et al., 2013).

Rats were trained on a task in which illumination of a left or right light indicated the location of reward. Prior to the spatial cue, an odor informed the rat of the size of reward and punishment that would result upon correct and incorrect performance, respectively. On two trial-types, there was no risk of punishment, just the potential of a large or small reward for a correct response. On a third trial-type, a small reward was promised for accurate performance, but there was also a risk of punishment (quinine) if the rat performed the task incorrectly. Rats were more accurate and faster to move down to the fluid well in response to the lights on large reward and quinine risk trials compared to small reward trials, demonstrating higher motivation on these trials relative to small reward trials (Figure 3A).

Remarkably, we found that single units in VS encoded both value and motivation. An example of the former is illustrated in Figure 3B. During odor sampling this neuron fired the most and the least for cues that predicted reward and punishment, respectively. This same neuron also fired during delivery of reward, but did not merely encode reward consumption, as evidenced by elevated firing when reward was omitted on error trials (Figure 3D). These results suggest that neurons in VS reflect the expected value of the reward during cue presentation and after the behavioral response. Thus, neurons in VS carry predictive value signals during odor sampling.

This relationship with value was mostly present in the activity of neurons that increased firing to both odor cues and reward delivery. Cue-responsive neurons that showed decreases in firing to reward delivery better reflected the degree of motivation associated conditioned stimuli, as illustrated in Figures 3C, E. For this neuron, activity was stronger for odor cues that predicted large reward and the risk of quinine punishment relative to small reward trials, consistent with representations of enhanced motivation.

Our results suggest that VS fulfills both evaluative and motivational functions, likely via separate neuronal populations, and might be required for integrating both types of information that are central to actor-critic models, as well frameworks that view the VS as a "limbic-motor" interface (Bissonette et al., 2013). All of this work features VS as a common junction point to act, possibly concurrently, to signal value and motivation which leads to the invigoration of particular behavioral actions over others. This idea is consistent with pharmacological studies suggested that DA in the VS had more to do with encoding incentive salience and motivation, rather than evaluative functions (Salamone, 1986; Salamone et al., 1991; McCullough and Salamone, 1992; Salamone, 1994; Koch et al., 2000; Berridge, 2007; Lex and Hauber, 2010; Salamone et al., 2012; Salamone and Correa, 2012; Nunes et al., 2013) and others that show that VS lesions disrupt rats ability to choice between differently valued rewards and to update behavior after devaluation of expected outcomes (Singh et al., 2010; Burton et al., 2013).

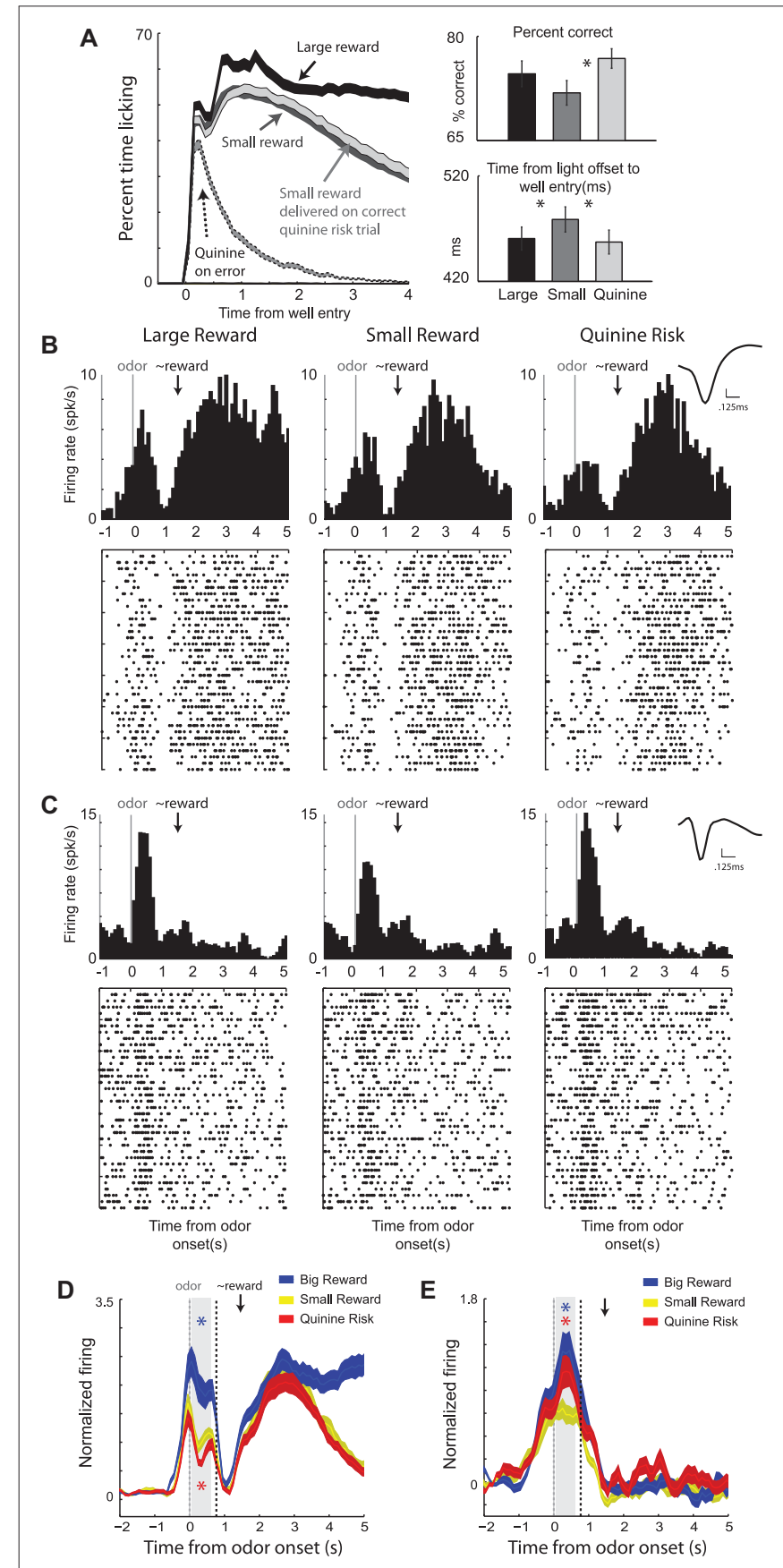

FIGURE 3 | Ventral striatal neurons encode both value and motivation. Rats performed a task during which two odors indicated the size (large or small) of the reward to be delivered at the end of the trial. If an error was committed on large and small reward trials, no reward was delivered. A third odor indicated that a small reward would be delivered on correct trials and that quinine would be delivered when rats responded to the wrong well. (A) Average lick rate over time during recording sessions. Black = delivery of large reward; Dark gray = delivery of small reward when there was no risk; Light gray = delivery of small reward when there was a risk of quinine. Dashed gray = delivery of quinine on risk trials during which rats went to the wrong fluid well. Average percent correct for the three trial types. Average time taken to move from the odor port to the fluid well in response to the spatial cue lights. (B-C) Single cell example of neurons that exhibited firing patterns consistent with value and motivation encoding on

(Continued) 


\section{FIGURE 3 | Continued}

correct trials for the 3 trial-types: large reward, small reward, and punishment. Activity is aligned to odor onset (left of dashed box) and reward delivery (right of dashed box). Inset: average waveform (not inverted). (D-E) Average normalized firing over all neurons that showed significant increases to both odor cues and reward delivery and those neurons that showed significant increased and decreased firing to cues and rewards, respectively. Firing rates were normalized by subtracting the baseline and dividing by the standard deviation. Ribbons represent standard error of the mean (SEM). Blue asterisks indicate significant differences between average firing during the odor epoch (gray bar) between large reward and small reward trials (blue versus yellow; $t$-test; $p<0.05$ ). Red asterisks are the comparison between quinine punishment and small reward trials (red versus yellow; $t$-test; $p<0.05$ ). The odor epoch did not include time when lights were on. Gray dashed $=$ onset of odors. Black dashed $=$ earliest possible time lights could turn on. Black arrow marks the average time of reward delivery. Adapted from Bissonette et al. (2013).

\section{DOPAMINE}

Signals from midbrain DA neurons play a critical role in reinforcement learning by providing a physiological correlate to the well-studied PE. This PE signal guides goal-directed behavior by informing the system which aspects of the environment are appetitive or aversive and initiating actions in order to obtain the good and avoid the bad (Schultz, 1997). Phasic bursts or pauses in neuronal activity, together with resulting neurotransmitter release, encodes this PE signal. The PE signal measures the difference between an expected outcome and the actual outcome in order to inform future behavior. A better-than-expected outcome activates dopaminergic neurons (positive PE) resulting in neurotransmitter release, while a worse-than-expected outcome (negative PE) induces a pause in dopaminergic firing. A fully predictable outcome elicits no change in firing of DA neurons. The same firing pattern applies for sensory cues that come to predict or give information about future rewards. Thus, DA firing and release tends to shift away from the delivery of primary rewards as they come to be predicted by cues during learning, resulting in more or less firing for cues that predict appetitive and aversive outcomes, respectively.

Based on the mismatch of expectation and consequence, the DA signal acts as a teaching mechanism, updating expectations and potential behavioral responses based on feedback received from the environment. DA neurons that fire synchronously and release DA as a result, are reinforced and are more likely to be activated in the future, promoting paired behaviors. The synchronized firing of dopaminergic neurons follows Hebb's idea that "neurons that fire together, wire together", but DA must be released in order for reinforcement learning to occur and the synaptic connection between neurons to be strengthened (Montague et al., 1996; Schultz, 1998; Bromberg-Martin et al., 2010). Most of the value signaling described in the brain areas above likely relies on DA to form associations between stimuli and outcomes during learning and decision-making.

Although PE signaling is often studied under paradigms that require animals to approach appetitive stimuli, PE theory holds true for DA signals related to avoiding aversive stimuli, such as air puff and shock. In primates, neurons that encode reward PEs are depressed by unexpected air puff and visual cues that predict them
(Bromberg-Martin et al., 2010). Furthermore, DA firing increases when an expected air puff is omitted, an event that is more appetitive or better than expected. A similar story is true in rats performing an instrumental escape-avoidance paradigm. Oleson et al. (2012) showed that phasic DA activity to cue presentation can predict if rats will successfully avoid an upcoming foot shock. Successful avoidance behavior was contingent upon DA release time-locked to the warning light. DA was released at the time of the avoided shock and during cue presentation of successful avoidance trials. Thus, as with appetitive paradigms, DA signals adhere to the general rule of firing more or less strongly for cues and outcomes that are better or worse than expected, respectively (Oleson et al., 2012). Importantly, this signal is dependent on input from OFC (Takahashi et al., 2011).

Notably, not all DA neurons transmit reward PE signals. Other, anatomically discrete, DA neurons appear to be more concerned about the motivational salience of appetitive and aversive stimuli (Matsumoto and Hikosaka, 2009). These DA neurons are triggered by both appetitive and aversive outcomes and the cues that predict them. In experiments where visual stimuli predict either reward or air-puff, these DA neurons fire more strongly for delivery of these outcomes and the cues that predict them, relative to neutral trials where there is no reward or air-puff. Interestingly, these two types of DA neurons, referred to as value and salience encoding neurons, are somewhat segregated in evaluative VTA and SNc, with value encoding cells mostly located in VTA and motivational salience DA neurons in SNc. There exists additional support for the idea that a subset of VTA DA neurons fire preferentially for aversive stimuli in rats, including social defeat, aversive foot shock (Anstrom et al., 2009; Brischoux et al., 2009) and pain inducing plantar injection of formalin to mice (Lammel et al., 2011). Evidence supports the notion that aversive-preferring or salience DA neurons project preferentially to the prefrontal cortex (PFC) and the core of nucleus accumbens (NAc), while reward-preferring or PE DA neurons project preferentially to the ventromedial PFC and the shell of NAc (Bromberg-Martin et al., 2010). Given this data, and the aforementioned idea that these DA neurons may be encoding salience, it seems likely that such a signal would be critical for driving attention/motivation to salient (appetitive or aversive) events promoting learning in regions that these neurons project to, whereas PEs signal might be critical for specifically updating representations of associations between events and their respective outcomes. Thus, DA signals value in the form of PEs, supporting functions related to approach, evaluation and value learning, and also motivational salience, supporting functions related to orienting, attention, and arousal (Bromberg-Martin et al., 2010).

\section{PARIETAL CORTEX AND ANTERIOR CINGULATE CORTEX (ACC)}

The most recent debate about value versus salience has focused on the parietal cortex. Parietal neurons have been shown to fire at a rate, dependent on the value of expected actions (actionvalue) and this signal is critical for making economic decisions about which action produces a better reward. Recently, Leathers and Olson (2012) reported that primate lateral intraparietal (LIP) 
neurons fire most strongly when a saccade is associated with a large versus small reward. Importantly, they also showed that the same neurons fired more strongly for cues that predicted a large versus small penalty. They suggest that the activity of LIP neurons encode the motivational salience of a cue, rather than the value necessary for decision-making.

In a rebuttal paper, Newsome et al. (2013) suggested that Leathers and Olson (2012) did not replicate delay-period activity as observed in previous experiments, calling into question the population of parietal neurons studied and the ability of the task to tap into these functions that capture action-value (Newsome et al., 2013). Subsequently, Leathers and Olson (2013) replied by pointing out that the key findings of their initial study, namely, that stronger activity was correlated with larger, rather than smaller penalty cues and that neurons signaled salience earlier in the trial during the decision process, were not in question, and that these correlates were found in cells that fired across delays the preceded the response. They suggest that the fact that salience, not value, is encoded by parietal cortex in this task suggests that value encoding is not a general function of parietal cortex. Further work is necessary to determine in what contexts parietal neurons might reflect salience versus value.

Other cortical areas thought to be involved in attention have been recently discussed in the realm of reward-related decisionmaking and reinforcement learning. Single neurons in macaque ACC show correlates related to unsigned PEs (Hayden et al., 2011), potentially signaling the necessity for additional resources in the face of signaling a need for behavioral modification. Using a variable size/delay task, Bryden et al. (2011) demonstrated rat ACC signaled errors and signaled the need for additional attentional resources during unexpected shifts in value in the same task used to investigate error signing in ABL (Bryden et al., 2011). Unlike activity in ABL, ACC firing was significantly stronger after both unexpected appetitive and aversive events during and before sampling of cues on subsequent trials. This signal likely reflects the salience or attention that is drawn to conditioned stimuli so that contingencies can be updated during learning.

These data are contrasted a bit by work in rhesus monkeys demonstrating ACC encoding of value as it relates to integrating previous outcomes with current choices (Kennerley et al., 2011). Indeed, additional research has suggested that medial PFC (which included parts of ACC) in rhesus monkeys signal both positive and negative PEs of action values (Matsumoto et al., 2007). Others have reported that distinct regions in ventromedial PFC encode rewards and punishments, with ventral and dorsal aspects being more active for appetitive and aversive trial-types, respectively (Monosov and Hikosaka, 2012). The fact that value and salience signals in ACC and parietal cortex appear to go hand in hand are consistent with the need for attentional control to ensure neural processes are prioritized depending on expected events and current behavioral strategy. Indeed neural correlates related to value predictions and spatial attention have been shown to be integrated in clusters of neurons in primate PFC (Kaping et al., 2011). Further research will need to be done to fully separate prefrontal and parietal contributions to signaling value, salience or both using a novel tasks that varies both appetitive and aversive outcomes.

\section{HUMAN STUDIES}

In parallel with the animal literature, human studies have implicated midbrain dopaminergic regions and their projection sites in the striatum and OFC during appetitive processing (Schultz et al., 2000; O’Doherty, 2004; Delgado, 2007; Haber and Knutson, 2010) and regions such as the amygdala and anterior insula during aversive processing (Adolphs and Tranel, 2000; LeDoux, 2000; Craig, 2002, 2009; Davis et al., 2010) Importantly, ventral and dorsal striatal regions are also involved during aversive processing (Jensen et al., 2003; Pruessner et al., 2004; Delgado et al., 2008), while there is some evidence for amygdala and anterior insula activity during appetitive processing (Everitt et al., 2003; Liu et al., 2011). Findings such as these question frameworks that promote appetitive and aversive processing purely in terms of distinct brain regions. Instead, they demonstrate that some of these regions encode factors such as salience and motivational "activation"not simply value.

Human studies have also attempted to dissociate the processing of value from factors such as salience, intensity, or arousal. These studies have used a wide range of tasks and focused on decision making and PE signals, as well as responses at different task phases, including cue and outcome-related activity. The overall logic used in human studies to attempt to dissociate value from other factors is similar to the one used in the animal literature (Figure 1). As before, three trial types are typically used: (1) appetitive, (2) aversive, and (3) neutral. If activity in a region represents "value" signals, then activation in that region for appetitive stimuli is expected to be greater than aversive stimuli, with responses to neutral somewhere in between. However, if activity represents salience or intensity, activation during both appetitive and aversive stimuli would be greater than that observed to neutral stimuli.

\section{DECISION MAKING}

Rangel and colleagues used a simple yet elegant decision-making task to disentangle fMRI signals related to value and salience (Litt et al., 2011). Participants were shown pictures of food items that ranged from being highly disliked to highly liked and were asked to make a choice whether or not they would like to eat the item after the experiment (participants in fact consumed these items following scanning). Consistent with previous animal work, value signals were observed in medial OFC (Figure 4A; as well as rostral ACC and PCC). Areas such as dorsal ACC, SMA, and insula generated salience type signals as they produced stronger responses for both "highly disliked" and "highly liked" items. Interestingly, signals in VS exhibited both value and salience type components consistent with the animal literature. As illustrated in Figure 4B, such signals in fact demonstrate that "hybrid" representations that code for both value and salience are also possible (Litt et al., 2011).

\section{REWARD CUE PROCESSING}

Adcock and colleagues utilized a simple cue followed by response task to dissociate value and salience signals in the VS and midbrain (Carter et al., 2009). In the experiment, cues signaled the chance to win monetary rewards ("gain") or the chance to avoid monetary losses ("loss") based on fast and accurate 


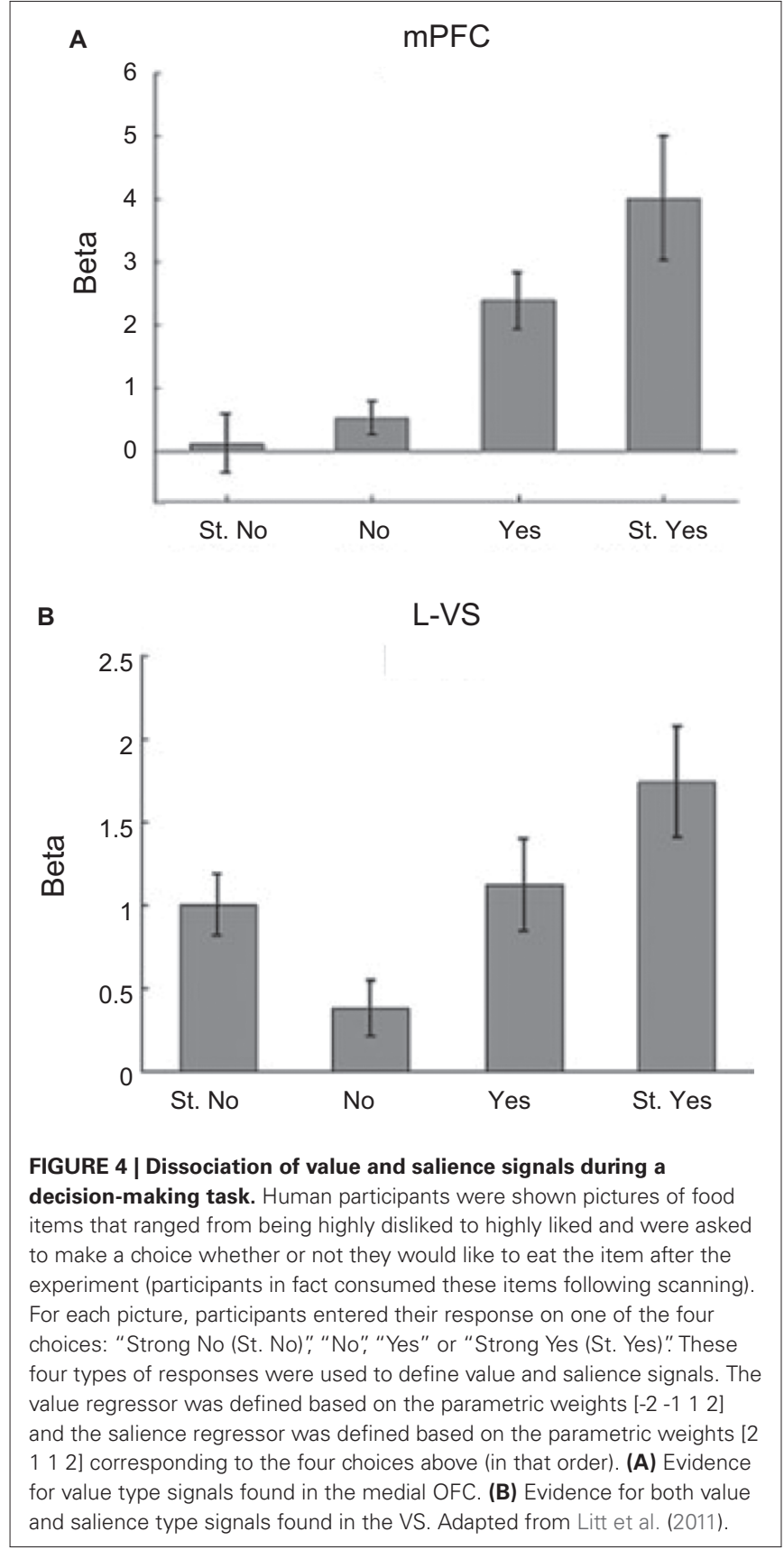

performance; baseline conditions involving no gain or loss ("nogain"/ "no-loss") were also employed. Cue-related activity in both NAc and VTA increased for both gain and loss trials, thus providing evidence for salience signals in both structures. Furthermore, in both regions, cue-related activity during gain and loss trials was positively correlated across participants providing further evidence for the salience account (Carter et al., 2009).

Cooper and Knutson, 2008 also found similar "salience" type responses in the NAc while participants processed cues that signal performance-dependent monetary gains or losses (Cooper and Knutson, 2008; but see Knutson et al., 2001; Breiter et al., 2001). Interestingly, when the outcomes were certain (i.e., independent

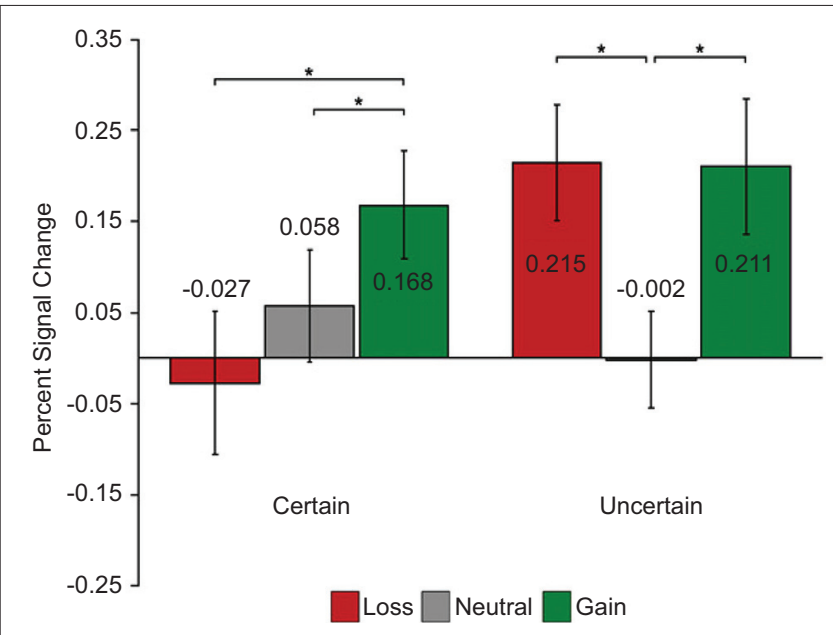

FIGURE 5 | Dissociation of value and salience signals during a reward processing task with humans. Each trial started with one of the six cue types: two levels of certainty ("certain"/" uncertain") crossed with three levels of reward ("gain"/"neutral"/"loss"). After a variable delay period, a visual target appeared and participants pressed a button while the target was on the screen. The duration of the target was adjusted dynamically in each condition separately to maintain approximately $67 \%$ task performance. During "gain" trials participants could earn monetary reward; during "loss" trials participants could lose money; during "neutral" trials no win/loss occurred. During "certain" trials, outcomes were independent of performance, whereas during "uncertain" trials outcomes were based on performance. Value signals were found in the NAc when outcomes were "certain" (i.e., independent of performance) and evidence for salience signals were found when outcomes were "uncertain" (i.e., based on performance). Adapted from Cooper and Knutson (2008).

of performance), they observed increased activity for gain compared to loss cues revealing value type signals in the NAc (Figure 5).

\section{REWARD OUTCOME PROCESSING}

Delgado and colleagues used a simple card-guessing task to investigate the neural responses related to reward and punishment feedback (Delgado et al., 2000). Participants were asked to guess whether the value of the unknown card would be greater or smaller than 5 . If they guessed correctly, they received monetary reward; for incorrect guesses monetary punishment was incurred. On neutral trials, where the value of the card turned out to be exactly 5, there was no reward or punishment. They observed value type signals in dorsal and VS during feedback, such that responses were greatest for reward, weaker for neutral and weakest for punishment trials (Delgado et al., 2000). In a follow-up study, they observed that value responses in dorsal striatum were present only when rewards were contingent upon behavior; they were absent when feedback was independent of the behavior (Tricomi et al., 2004).

\section{RESPONSES TO UNCONDITIONED STIMULI (US)}

Another class of experiment has investigated responses to pleasant or unpleasant sensory stimuli themselves. In one case, Anderson and colleagues independently varied the intensity and valence of olfactory stimuli by using pleasant and unpleasant odorants 
of high and low intensity (Anderson et al., 2003). Responses in amygdala reflected the intensity of the odor, not the valence. In contrast, the OFC revealed value type responses. Specifically, responses in medial OFC were stronger for pleasant compared to unpleasant odors whereas responses in lateral OFC were stronger for unpleasant compared to pleasant odors (Anderson et al., 2003). In a similar study with gustatory stimuli, Parrish and colleagues independently varied the intensity and valence of liquids and found similar evidence for salience signals in the amygdala and value signals in the OFC (Small et al., 2003).

These two studies suggested a general role for the amygdala in the coding of stimulus intensity. Yet, a follow-up study by Dolan and colleagues using olfactory stimuli demonstrated that the activity in the amygdala is best conceptualized in terms of an interaction between intensity and valence-that is, an interaction between salience and value (Winston et al., 2005). The authors used high/low concentrations of pleasant/unpleasant/neutral odors and reported that activity in the amygdala was increased for high (versus low) intensity odors only when they were pleasant or unpleasant, but not when the odor was neutral. Related valence by intensity interactions have also been observed in the amygdala in the animal literature (Paton et al., 2006).

\section{PREDICTION ERROR SIGNALS}

Several functional MRI studies have used Pavlovian conditioning paradigms to attempt to dissociate value and salience encoding based on the pattern of PE signals.

The logic of these experiments is that regions encoding value would exhibit opposite PE signals for appetitive and aversive stimuli, where a positive PE response would be observed when an appetitive US is delivered or when an aversive US is omitted, and a negative PE response would be observed when an aversive US is delivered or when an appetitive US is omitted. In contrast, regions encoding salience would exhibit similar PE signals for both appetitive and aversive stimuli, where a positive PE would be observed for reinforced outcomes and a negative PE for unreinforced outcomes. Using this logic, Jensen et al. (2007) reported salience type PE signals in the VS, bilateral anterior insula and medial OFC. Similarly, Dreher and colleagues reported salience type PE signals in the striatum (bilateral putamen) and amygdala (as well as anterior insula and ACC) (Metereau and Dreher, 2013). Notably, these studies did not find evidence for value type PE signals in the human brain.

\section{Salience signals or analysis confound?}

A challenge with functional MRI studies of PEs is that the PE signal is confounded with that of US delivery (Niv, 2009). Specifically, the PE is positive when the US is delivered and negative when the US is withheld. As a consequence, a traditional multiple regression analysis could implicate regions in the generation of $\mathrm{PE}$ signals when they are actually responding simply to US delivery. To control for this confound, researchers typically include an additional US regressor (i.e., covariate) for each trial type along with a "parametric" regressor to capture variance related to the PE. Figure 6 illustrates this situation. Unfortunately, this strategy could itself spuriously lead to PE-related activity. For instance, imagine a region that simply responds to the US (e.g., insula activated by electric shock) but has no role in encoding PEs. When a single US regressor tries to account for variance during both reinforced and unreinforced shock outcomes as typically done, the estimated regression coefficient would be somewhere midway between the activity evoked by reinforced and unreinforced outcomes. Hence, the unaccounted variance in this region would have a positive value (i.e., residual) during reinforced outcomes and a negative value (i.e., residual) during unreinforced outcomes. This overall pattern qualitatively matches the shape of the PE regressor. Therefore, one could spuriously detect PE type signals in regions that simply respond to US delivery. Some functional MRI studies have avoided this problem (McClure et al., 2003; D’Ardenne et al., 2008).

\section{SIMULTANEOUS MANIPULATION OF APPETITIVE AND AVERSIVE STIMULI}

The work that we have discussed so far has considered appetitive and aversive information in isolation. A few recent studies have used stimuli that simultaneously incorporate appetitive and aversive information to further understand the role of different brain regions in processing value and/or salience type signals.

In a decision making paradigm, Tobler and colleagues investigated two kinds of salience signals that can only be distinguished in decisions that involve simultaneous costs and benefits (Kahnt and Tobler, 2013). When appetitive and aversive stimuli are presented in isolation, salience can be captured by the absolute value of the stimulus (i.e., $\mid$ App $\mid$ or $\mid$ Aver|). But when appetitive and aversive stimuli are presented simultaneously, salience could be of two types: one based on the absolute value of the "total" (i.e., |App + Aver|), another based on the sum of the absolute values (i.e., $\mid$ App $|+|$ Aver $\mid)$. Tobler and colleagues found evidence for the latter type of salience signal in a site in the temporo-parietal junction (TPJ). Consistent with previous studies, they also found evidence for value based signals in the VS (though they did not detect salience-related signals in the VS). A handful of additional decision making studies have used simultaneous appetitive and aversive stimuli to the same effect (Talmi et al., 2009; Park et al., 2011).

In a recent study, we were also interested in characterizing responses to stimuli containing both appetitive and aversive information. In the study, we investigated the interactions between the anticipation of reward and/or threat (Choi et al., 2013). Participants were presented with four advance cues to alert them of the possibility of: (1) reward/no shock, (2) reward/shock, (3) no reward/no shock, and (4) no reward/shock. Reward was contingent on performance whereas shock was independent of performance. This procedure juxtaposed two competing ideas. One, in line with what we have been discussing, for conditions involving simultaneous reward and threat, enhanced activity would reflect a type of salience signal (given the presence of both dimensions); the other predicted that the presence of both appetitive and aversive stimuli would lead to a "competition" between them. Skin conductance data acquired during scanning demonstrated an interaction between reward and threat processing, such that reward and threat effects were reduced by threat and reward, respectively. In terms of brain responses, several brain 
A

$$
\begin{aligned}
& \begin{array}{lll}
\text { CUE DELAY OUTCOME } &
\end{array}
\end{aligned}
$$

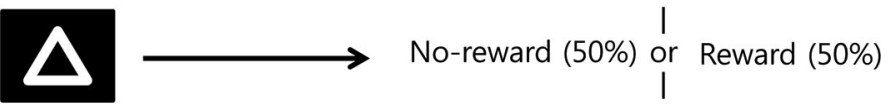

$$
\begin{aligned}
& \mathrm{CS}_{\text {reward }} \quad \text { Prediction error }=(\text { Actual }- \text { Expected }) \text { outcome }
\end{aligned}
$$

B

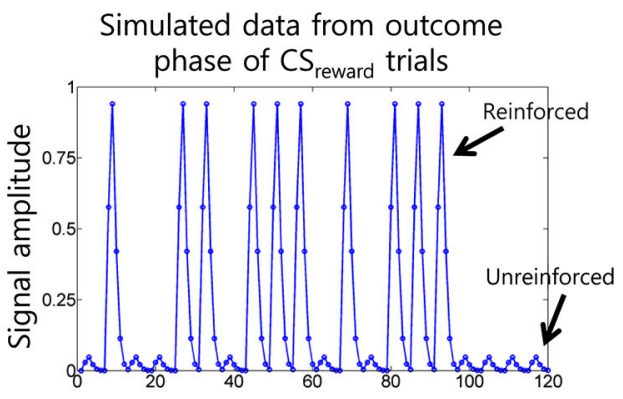

c Model fit from regression analysis on simulated data using one regressor

to model both reinforced and unreinforced outcome events

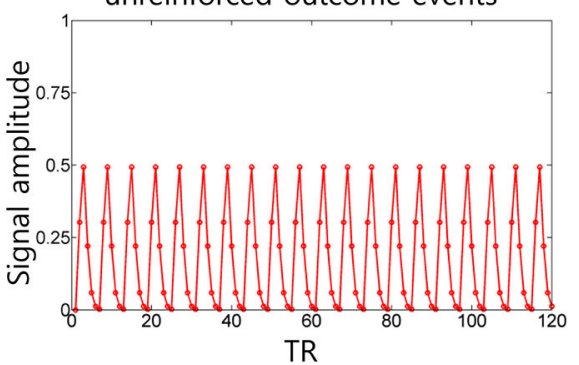

D

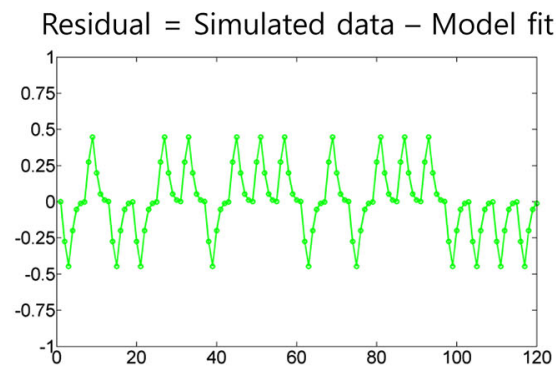

E

Prediction error regressor created based on Rescorla-Wagner model

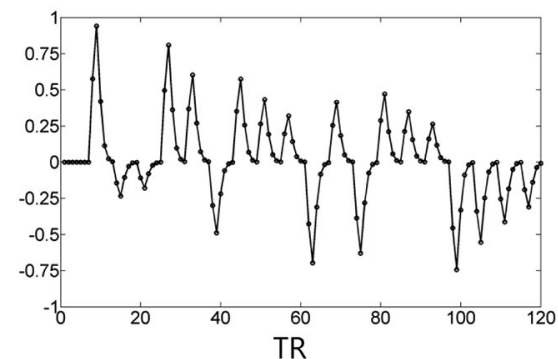

$\mathbf{F}$

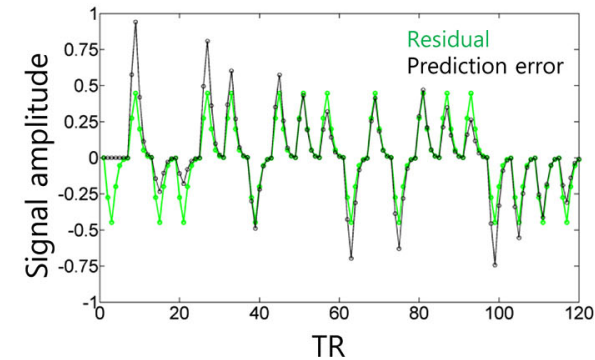

FIGURE 6 | Prediction error (PE) signal analysis and potential confounds in fMRI analysis. (A) In a typical appetitive Pavlovian conditioning paradigm,

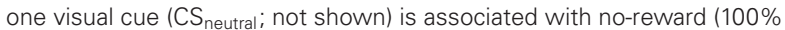
probability) whereas a second visual cue $\left(\mathrm{CS}_{\text {reward }}\right)$ is associated with $50 \%$ probability of receiving reward. PE (i.e., actual minus expected outcomes) measured at the outcome phase of $\mathrm{CS}_{\text {reward }}$ trials. (B) Simulated fMRI time series data (blue) generated using 10 reinforced and 10 unreinforced outcome events of $\mathrm{CS}_{\text {reward }}$ trials in a pseudorandom order with $15 \mathrm{~s}$ separation between events at a typical TR of $2.5 \mathrm{~s}$. For the sake of simplicity, we have not considered $\mathrm{CS}_{\text {neutral }}$ trials and the cue phase of $\mathrm{CS}_{\text {reward }}$ trials (which are typically modeled as separate regressors) and no noise was added to the simulated data. (C) When a single outcome phase regressor is used to account for variance during both reinforced and unreinforced outcomes of
CS reward trials as typically done, the estimated regression coefficient would be somewhere midway between the activity evoked by reinforced and unreinforced outcomes, as demonstrated by the estimated data fit (red). (D) Hence, the residual time series data (green) will show positive values during reinforced outcome events and negative values during unreinforced outcome events. (E) Parametric regressor based on trial-by-trial fluctuations of PE

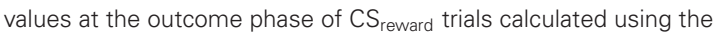
Rescorla-Wagner rule (Rescorla and Wagner, 1972) (a learning rate of 0.25 was used as often used in $\mathrm{fMRI}$ studies). (F) The residual time series and the $\mathrm{PE}$ regressors are overlaid to show the high correlation between them. Because of this, unaccounted variance during the outcome phase related activity of $\mathrm{CS}_{\text {reward }}$ trials could be "spuriously" accounted by the PE regressor. 
areas exhibited this type of reward-threat trade-off, including midbrain, caudate, putamen, and anterior insula.

\section{LIMITATIONS OF FUNCTIONAL MRI STUDIES}

Single unit recordings in midbrain and VS have identified separate populations of neurons coding for value and salience (Matsumoto and Hikosaka, 2009; Bissonette et al., 2013). The coarse spatial resolution of typical functional MRI studies prevents them from measuring separate signals for the separate populations. Indeed, in some cases, the measured fMRI response could be based on the combined activity of underlying value and salience processing neurons. Consider also single-unit studies revealing separate populations of neurons coding for appetitive and aversive stimuli (e.g., Ungless et al., 2004). In such cases, if a region shows salience type fMRI responses, it could be due to the contribution from separate underlying neuronal populations, which would be engaged by appetitive and aversive stimuli. But here it is worthwhile noting that some single-unit studies in humans (Laxton et al., 2013) and monkeys (Amemori and Graybiel, 2012; Monosov and Hikosaka, 2012) have revealed neurons coding for appetitive and aversive stimuli within the same population. These studies, together with human studies that revealed the dependence of valence signals on their salience (e.g., during active versus passive task processing) are consistent, in broad terms, with meta-analytic findings reporting little evidence for processing of discrete emotion categories in distinct brain regions (Lindquist et al., 2012).

A second issue is that the sluggish nature of hemodynamic responses makes it challenging to unambiguously disambiguate responses to different task phases, for example, "cue", "anticipation", and "outcome" phases. In contrast, the high temporal resolution of electrophysiology provides rich information to investigate the dynamics of value and salience representations (e.g., Matsumoto and Hikosaka, 2009). Importantly, high temporal resolution in single unit studies also allows the investigation of responses at the outcome phase independent from short-latency responses linked to the sensory properties of US (Fiorillo et al., 2013).

\section{DISCUSSION}

In this paper, we reviewed how the brain encodes appetitive and aversive events in both non-human animals and humans. This line of research is important, as understanding the neural processing behind appetitive and aversive stimuli is critical to understand what drives different behavioral responses. Much of the literature has approached these problems by studying how an animal associates a particular odor with a potential predator, or by investigating how a visual cue is associated with a tasty ripe fruit. The behaviors enacted in each of those scenarios would be, naturally, very different (alertly avoid, or boldly engage). However, few situations in real life are as cut and dry. Often, predators prowl near locations and objects that prey animals enjoy (near watering holes, food sources, migratory routes, following the mating calls of animals), and attaining rewards may require dealing with cues that signal aversive events (extracting honey from wild bees, picking fruit from thorny plants).
As reviewed here, despite differences in the species investigated and the techniques utilized, some consensus has started to emerge regarding the encoding of both value and other related motivational signals. Yet, both apparent discrepancies and unresolved issues remain and need to be addressed in future work. The combined evidence reveals that the OFC has a representation of value that is relatively "pure". The VS carries both value and salience signals that appear to be generated by different neuronal populations. Amygdala responses are modulated by stimulus intensity, though the signal is clearly moderated by the valence (i.e., value) of the stimulus.

Taken together, the work described here suggests a circuit by which OFC represents value expectancies necessary for guiding decision-making and learning. These signals depend on ABL, which not only encodes associative appetitive and aversive information during sampling of conditioned stimuli and across states, but integrates value and intensity/salience during delivery of appetitive and aversive outcomes. OFC and ABL both broadcast this information to VS and DA neurons, which carry both evaluative (VTA) and motivational salience ( $\mathrm{SNc}$ ) signals in separate populations of neurons (Figure 7). PE signals generated by VTA DA neurons provide feed-forward information to more dorsalmedial and dorsal-lateral regions in striatum, which are critical for goal-directed and habitual behaviors, respectively. Parietal and ACC likely increase attentional control to ensure that neural processes are prioritized depending on expected actions and unsigned errors in reward prediction. From this research it is clear that we have to continue to compare and contrast how neural systems reconcile both appetitive and aversive stimuli, and continue to disambiguate the meaning of signals modulated by valence and how they relate to subsequent behavior.

In terms of issues that will drive future research, we can highlight at least three. The first concerns the types of representation

Prefrontal
Orbitofrontal Amygdala
FiGURE 7 I Circuit diagram demonstrating connectivity between brain
regions and their relative location on a sliding scale of value to
salience, with the influence of DA signaling integrated. Gradient bars
represent relative encoding of value and salience. Orbitofrontal
Cortex—OFC, Prefrontal Cortex—PFC, Basolateral Amygdala—ABL,
Anterior Cingulate Cortex—ACC, Parietal Cortex-Parietal, Dorsal Medial
Striatum—DMS, Dorsal Lateral Striatum—DLS, Ventral Tegmental
Area—VTA, Substantia Nigra compacta—SNc, Superior Colliculus-SC,
GP—Globus Pallidus, Thalamus—-Thal, Substantia Nigra reticulata—SNr,
Premotor Cortex—PM.


in parietal cortex. Are they closer to value based or are they better conceptualized in terms of salience? The second concerns the study of PEs in the human brain with functional MRI. As illustrated, it can be challenging to separate "true" PEs from responses to US delivery. Consequently, it is unclear at the moment if PE signals reflect salience representations across a wider set of regions of the brain as suggested by the human work (e.g., insula, dorsal striatum, amygdala, ACC), or if in some cases they may have resulted from responses to the US itself. This is an area that we believe future work is clearly needed, both non-human work investigating a wider group of regions, and human work that more effectively deals with potential confounds. A third issue is related to functional MRI as a methodology. Both issues of spatial and temporal resolution pose important challenges to being able to investigate value signals in the brain. These clearly need to be addressed more effectively; perhaps with newer techniques that allow finer temporal sampling (every $500 \mathrm{~ms}$ or less) of hemodynamic responses and finer spatial resolution (less than $1 \mathrm{~mm}$ ) can go some way toward mitigating current issues (though higher temporal sampling can only go so far given the low-pass nature of the hemodynamic response). In any case, we anticipate exciting times ahead as the field advances the understanding of how the brain encodes value and other motivational variables.

\section{ACKNOWLEDGMENTS}

Support for this work was provided in part by the National Institute of Mental Health (R01MH071589 to Luiz Pessoa) and the National Institute on Drug Abuse (R01DA031695, Matthew R. Roesch).

\section{REFERENCES}

Adolphs, R., and Tranel, D. (2000). "Emotion recognition and the human amygdala," in The Amygdala: A Functional Anlysis, ed J. P. Aggleton (New York: Oxford University Press), 587-630.

Amemori, K., and Graybiel, A. M. (2012). Localized microstimulation of primate pregenual cingulate cortex induces negative decision-making. Nat. Neurosci. 15 , 776-785. doi: 10.1038/nn.3088

Anderson, A. K. (2005). Affective influences on the attentional dynamics supporting awareness. J. Exp. Psychol. Gen. 134, 258-281. doi: 10.1037/0096-3445.134. 2.258

Anderson, A. K., Christoff, K., Stappen, I., Panitz, D., Ghahremani, D. G., Glover, G., et al. (2003). Dissociated neural representations of intensity and valence in human olfaction. Nat. Neurosci. 6, 196-202. doi: 10.1038/nn1001

Anderson, B. A., Laurent, P. A., and Yantis, S. (2011). Value-driven attentional capture. Proc. Natl. Acad. Sci. U S A 108, 10367-10371. doi: 10.1073/pnas. 1104047108

Anstrom, K. K., Miczek, K. A., and Budygin, E. A. (2009). Increased phasic dopamine signaling in the mesolimbic pathway during social defeat in rats. Neuroscience 161, 3-12. doi: 10.1016/j.neuroscience.2009.03.023

Belova, M. A., Paton, J. J., Morrison, S. E., and Salzman, C. D. (2007). Expectation modulates neural responses to pleasant and aversive stimuli in primate amygdala. Neuron 55, 970-984. doi: 10.1016/j.neuron.2007.08.004

Berridge, K. C., and Robinson, T. E. (1998). What is the role of dopamine in reward: hedonic impact, reward learning, or incentive salience? Brain Res. Brain Res. Rev. 28, 309-369. doi: 10.1016/s0165-0173(98)00019-8

Berridge, K. C. (2007). The debate over dopamine's role in reward: the case for incentive salience. Psychopharmacology (Berl) 191, 391-431. doi: 10. 1007/s00213-006-0578-x

Bissonette, G. B., Burton, A. C., Gentry, R. N., Goldstein, B. L., Hearn, T. N., Barnett, B. R., et al. (2013). Separate populations of neurons in ventral striatum encode value and motivation. PLoS One 8:e64673. doi: 10.1371/journal.pone. 0064673
Blokland, A. (1998). Reaction time responding in rats. Neurosci. Biobehav. Rev. 22, 847-864. doi: 10.1016/s0149-7634(98)00013-x

Breiter, H. C., Aharon, I., Kahneman, D., Dale, A., and Shizgal, P. (2001). Functional imaging of neural responses to expectancy and experience of monetary gains and losses. Neuron 30, 619-639. doi: 10.1016/s0896-6273(01)00303-8

Brischoux, F., Chakraborty, S., Brierley, D. I., and Ungless, M. A. (2009). Phasic excitation of dopamine neurons in ventral VTA by noxious stimuli. Proc. Natl. Acad. Sci. U S A 106, 4894-4899. doi: 10.1073/pnas.0811507106

Bromberg-Martin, E. S., Matsumoto, M., and Hikosaka, O. (2010). Dopamine in motivational control: rewarding, aversive and alerting. Neuron 68, 815-834. doi: 10.1016/j.neuron.2010.11.022

Bryden, D. W., Johnson, E. E., Tobia, S. C., Kashtelyan, V., and Roesch, M. R. (2011). Attention for learning signals in anterior cingulate cortex. J. Neurosci. 31, 1826618274. doi: 10.1523/JNEUROSCI.4715-11.2011

Burton, A. C., Bissonette, G. B., Lichtenberg, N. T., Kashtelyan, V., and Roesch, M. R. (2013). Ventral striatum lesions enhance stimulus and response encoding in dorsal striatum. Biol. Psychiatry 75, 132-139. doi: 10.1016/j.biopsych.2013. 05.023

Cardinal, R. N., Parkinson, J. A., Hall, J., and Everitt, B. J. (2002b). Emotion and motivation: the role of the amygdala, ventral striatum and prefrontal cortex. Neurosci. Biobehav. Rev. 26, 321-352. doi: 10.1016/s0149-7634(02)00 007-6

Cardinal, R. N., Parkinson, J. A., Lachenal, G., Halkerston, K. M., Rudarakanchana, N., Hall, J., et al. (2002a). Effects of selective excitotoxic lesions of the nucleus accumbens core, anterior cingulate cortex and central nucleus of the amygdala on autoshaping performance in rats. Behav. Neurosci. 116, 553-567. doi: 10. 1037/0735-7044.116.4.553

Cardinal, R. N., Pennicott, D. R., Sugathapala, C. L., Robbins, T. W., and Everitt, B. J. (2001). Impulsive choice induced in rats by lesions of the nucleus accumbens core. Science 292, 2499-2501. doi: 10.1126/science.1060818

Carelli, R. M., and Deadwyler, S. A. (1994). A comparison of nucleus accumbens neuronal firing patterns during cocaine self-administration and water reinforcement in rats. J. Neurosci. 14, 7735-7746.

Carter, R. M., Macinnes, J. J., Huettel, S. A., and Adcock, R. A. (2009). Activation in the VTA and nucleus accumbens increases in anticipation of both gains and losses. Front. Behav. Neurosci. 3:21. doi: 10.3389/neuro.08.021.2009

Choi, J. M., Padmala, S., Spechler, P., and Pessoa, L. (2013). Pervasive competition between threat and reward in the brain. Soc. Cogn. Affect. Neurosci. doi: 10. 1093/scan/nst053. [Epub ahead of print].

Cooper, J. C., and Knutson, B. (2008). Valence and salience contribute to nucleus accumbens activation. Neuroimage 39, 538-547. doi: 10.1016/j.neuroimage. 2007.08.009

Craig, A. D. (2002). How do you feel? Interoception: the sense of the physiological condition of the body. Nat. Rev. Neurosci. 3, 655-666.

Craig, A. D. (2009). How do you feel-now? The anterior insula and human awareness. Nat. Rev. Neurosci. 10, 59-70. doi: 10.1038/nrn2555

Cromwell, H. C., Hassani, O. K., and Schultz, W. (2005). Relative reward processing in primate striatum. Exp. Brain Res. 162, 520-525. doi: 10.1007/s00221-0052223-z

D’Ardenne, K., McClure, S. M., Nystrom, L. E., and Cohen, J. D. (2008). BOLD responses reflecting dopaminergic signals in the human ventral tegmental area. Science 319, 1264-1267. doi: 10.1126/science.1150605

Davis, M., Walker, D. L., Miles, L., and Grillon, C. (2010). Phasic vs sustained fear in rats and humans: role of the extended amygdala in fear vs anxiety. Neuropsychopharmacology 35, 105-135. doi: 10.1038/npp.2009.109

Daw, N. D., Kakade, S., and Dayan, P. (2002). Opponent interactions between serotonin and dopamine. Neural Netw. 15, 603-616. doi: 10.1016/s08936080(02)00052-7

Day, J. J., Jones, J. L., and Carelli, R. M. (2011). Nucleus accumbens neurons encode predicted and ongoing reward costs in rats. Eur. J. Neurosci. 33, 308-321. doi: 10. 1111/j.1460-9568.2010.07531.x

Delgado, M. R. (2007). Reward related responses in the human striatum. Ann. N Y Acad. Sci. 1104, 70-88. doi: 10.1196/annals.1390.002

Delgado, M. R., Li, J., Schiller, D., and Phelps, E. A. (2008). The role of the striatum in aversive learning and aversive prediction errors. Philos. Trans. R. Soc. Lond. B Biol. Sci. 363, 3787-3800. doi: 10.1098/rstb.2008.0161

Delgado, M. R., Nystrom, L. E., Fissell, C., Noll, D. C., and Fiez, J. A. (2000). Tracking the hemodynamic responses to reward and punishment in the striatum. J. Neurophysiol. 84, 3072-3077. 
Di Chiara, G. (2002). Nucleus accumbens shell and core dopamine: differential role in behavior and addiction. Behav. Brain Res. 137, 75-114. doi: 10.1016/s01664328(02)00286-3

Di Ciano, P., Cardinal, R. N., Cowell, R. A., Little, S. J., and Everitt, B. J. (2001). Differential involvement of NMDA, AMPA/kainate and dopamine receptors in the nucleus accumbens core in the acquisition and performance of pavlovian approach behavior. J. Neurosci. 21, 9471-9477.

Everitt, B. J., Cardinal, R. N., Parkinson, J. A., and Robbins, T. W. (2003). Appetitive behavior: impact of amygdala-dependent mechanisms of emotional learning. Ann. N Y Acad. Sci. 985, 233-250. doi: 10.1111/j.1749-6632.2003.tb0 7085.x

Fiorillo, C. D., Song, M. R., and Yun, S. R. (2013). Multiphasic temporal dynamics in responses of midbrain dopamine neurons to appetitive and aversive stimuli. J. Neurosci. 33, 4710-4725. doi: 10.1523/jneurosci.3883-12.2013

Floresco, S. B., St Onge, J. R., Ghods-Sharifi, S., and Winstanley, C. A. (2008). Cortico-limbic-striatal circuits subserving different forms of cost-benefit decision making. Cogn. Affect. Behav. Neurosci. 8, 375-389. doi: 10.3758/cabn. 8.4.375

Ghods-Sharifi, S., and Floresco, S. B. (2010). Differential effects on effort discounting induced by inactivations of the nucleus accumbens core or shell. Behav. Neurosci. 124, 179-191. doi: 10.1037/a0018932

Giertler, C., Bohn, I., and Hauber, W. (2003). The rat nucleus accumbens is involved in guiding of instrumental responses by stimuli predicting reward magnitude. Eur. J. Neurosci. 18, 1993-1996. doi: 10.1046/j.1460-9568.2003. 02904.x

Goense, J. B. M., and Logothetis, N. K. (2008). Neurophysiology of the BOLD fMRI signal in awake monkeys. Curr. Biol. 18, 631-640. doi: 10.1016/j.cub.2008.03.054

Goldstein, B. L., Barnett, B. R., Vasquez, G., Tobia, S. C., Kashtelyan, V., Burton, A. C., et al. (2012). Ventral striatum encodes past and predicted value independent of motor contingencies. J. Neurosci. 32, 2027-2036. doi: 10.1523/jneurosci. 5349-11.2012

Gruber, A. J., Hussain, R. J., and O'Donnell, P. (2009). The nucleus accumbens: a switchboard for goal-directed behaviors. PLoS One 4:e5062. doi: 10. 1371/journal.pone.0005062

Haber, S. N., and Knutson, B. (2010). The reward circuit: linking primate anatomy and human imaging. Neuropsychopharmacology 35, 4-26. doi: 10.1038/npp. 2009.129

Haber, S. N., Fudge, J. L., and McFarland, N. R. (2000). Striatonigrostriatal pathways in primates form an ascending spiral from the shell to the dorsolateral striatum. J. Neurosci. 20, 2369-2382.

Hatfield, T., Han, J. S., Conley, M., Gallagher, M., and Holland, P. (1996). Neurotoxic lesions of basolateral, but not central, amygdala interfere with Pavlovian second-order conditioning and reinforcer devaluation effects. J. Neurosci. 16, 5256-5265.

Hayden, B. Y., Heilbronner, S. R., Pearson, J. M., and Platt, M. L. (2011). Surprise signals in anterior cingulate cortex: neuronal encoding of unsigned reward prediction errors driving adjustment in behavior. J. Neurosci. 31, 4178-4187. doi: 10.1523/jneurosci.4652-10.2011

Hosokawa, T., Kato, K., Inoue, M., and Mikami, A. (2007). Neurons in the macaque orbitofrontal cortex code relative preference of both rewarding and aversive outcomes. Neurosci. Res. 57, 434-445. doi: 10.1016/j.neures.2006.12.003

Houk, J. C., Adams, J. L., and Barto, A. G. (1995). "A model of how the basal ganglia generate and use neural signals that predict reinforcement," in Models of Information Processing the Basal Ganglia, eds J. C. Houk, J. L. Davis and D. G. Beiser (Cambridge, USA: MIT press), 249-270.

Ikemoto, S., and Panksepp, J. (1999). The role of nucleus accumbens dopamine in motivated behavior: a unifying interpretation with special reference to reward-seeking. Brain Res. Brain Res. Rev. 31, 6-41. doi: 10.1016/s0165-0173(99) 00023-5

Ikemoto, S. (2007). Dopamine reward circuitry: two projection systems from the ventral midbrain to the nucleus accumbens-olfactory tubercle complex. Brain Res. Rev. 56, 27-78. doi: 10.1016/j.brainresrev.2007.05.004

Ito, M., and Doya, K. (2009). Validation of decision-making models and analysis of decision variables in the rat basal ganglia. J. Neurosci. 29, 9861-9874. doi: 10 . 1523/jneurosci.6157-08.2009

Janak, P. H., Chen, M. T., and Caulder, T. (2004). Dynamics of neural coding in the accumbens during extinction and reinstatement of rewarded behavior. Behav. Brain Res. 154, 125-135. doi: 10.1016/j.bbr.2004.02.003
Jensen, J., McIntosh, A. R., Crawley, A. P., Mikilis, D. J., Remington, G., and Kapur, S. (2003). Direct activation of the ventral striatum in anticipation of aversive stimuli. Neuron 40, 1251-1257. doi: 10.1016/s0896-6273(03)0 0724-4

Jensen, J., Smith, A. J., Willeit, M., Crawley, A. P., Mikulis, D. J., Vitcu, I., et al. (2007). Separate brain regions code for salience vs. valence during reward prediction in humans. Hum. Brain Mapp. 28, 294-302. doi: 10.1002/hbm. 20274

Joel, D., Niv, Y., and Ruppin, E. (2002). Actor-critic models of the basal ganglia: new anatomical and computational perspectives. Neural Netw. 15, 535-547. doi: 10. 1016/s0893-6080(02)00047-3

Kahnt, T., and Tobler, P. N. (2013). Salience signals in the right temporoparietal junction facilitate value-based decisions. J. Neurosci. 33, 863-869. doi: 10. 1523/jneurosci.3531-12.2013

Kalenscher, T., Lansink, C. S., Lankelma, J. V., and Pennartz, C. M. (2010). Rewardassociated gamma oscillations in ventral striatum are regionally differentiated and modulate local firing activity. J. Neurophysiol. 103, 1658-1672. doi: 10. 1152/jn.00432.2009

Kaping, D., Vinck, M., Hutchison, R. M., Everling, S., and Womelsdorf, T. (2011). Specific contributions of ventromedial, anterior cingulate, and lateral prefrontal cortex for attentional selection and stimulus valuation. PLoS Biol. 9:e1001224. doi: 10.1371/journal.pbio.1001224

Kennerley, S. W., Behrens, T. E., and Wallis, J. D. (2011). Double dissociation of value computations in orbitofrontal and anterior cingulate neurons. Nat. Neurosci. 14, 1581-1589. doi: 10.1038/nn.2961

Kim, H., Sul, J. H., Huh, N., Lee, D., and Jung, M. W. (2009). Role of striatum in updating values of chosen actions. J. Neurosci. 29, 14701-14712. doi: 10. 1523/jneurosci.2728-09.2009

Knutson, B., Adams, C. M., Fong, G. W., and Hommer, D. (2001). Anticipation of increasing monetary reward selectively recruits nucleus accumbens. J. Neurosci. 21:RC159.

Koch, M., Schmid, A., and Schnitzler, H. U. (2000). Role of muscles accumbens dopamine D1 and D2 receptors in instrumental and Pavlovian paradigms of conditioned reward. Psychopharmacology (Berl) 152, 67-73. doi: 10 . 1007/s002130000505

Lammel, S., Ion, D. I., Roeper, J., and Malenka, R. C. (2011). Projection-specific modulation of dopamine neuron synapses by aversive and rewarding stimuli. Neuron 70, 855-862. doi: 10.1016/j.neuron.2011.03.025

Lang, P. J., and Davis, M. (2006). Emotion, motivation and the brain: reflex foundations in animal and human research. Prog. Brain Res. 156, 3-29. doi: 10. 1016/s0079-6123(06)56001-7

Lansink, C. S., Goltstein, P. M., Lankelma, J. V., and Pennartz, C. M. (2010). Fast-spiking interneurons of the rat ventral striatum: temporal coordination of activity with principal cells and responsiveness to reward. Eur. J. Neurosci. 32, 494-508. doi: 10.1111/j.1460-9568.2010. 07293.x

Laxton, A. W., Neimat, J., Davis, K. D., Womelsdorf, T., Hutchinson, W. D., Dostrovsky, J. O., et al. (2013). Neuronal coding of implicit emotion categories in the subcallosal cortex in patients with depression. Biol. Psychiatry 74, 714719. doi: 10.1016/j.biopsych.2013.03.029

Leathers, M. L., and Olson, C. R. (2012). In monkeys making value-based decisions, LIP neurons encode cue salience and not action value. Science 338, 132-135. doi: 10.1126/science. 1226405

Leathers, M. L., and Olson, C. R. (2013). Response to comment on "In monkeys making value-based decisions, LIP neurons encode cue salience and not action value". Science 340, 430. doi: 10.1126/science.123 3367

LeDoux, J. E. (2000). Emotion circuits in the brain. Annu. Rev. Neurosci. 23, 155 184. doi: 10.1146/annurev.neuro.23.1.155

Lex, B., and Hauber, W. (2010). The role of nucleus accumbens dopamine in outcome encoding in instrumental and pavlovian conditioning. Neurobiol. Learn. Mem. 93, 283-290. doi: 10.1016/j.nlm.2009.11.002

Lindquist, K. A., Wager, T. D., Kober, H., Bliss-Moreau, E., and Barrett, L. F. (2012). The brain basis of emotion: a meta-analytic review. Behav. Brain Sci. 35, 121143. doi: 10.1017/s0140525x11000446

Litt, A., Plassmann, H., Shiv, B., and Rangel, A. (2011). Dissociating valuation and saliency signals during decision-making. Cereb. Cortex 21, 95-102. doi: 10. 1093/cercor/bhq065 
Liu, X., Hairston, J., Schrier, M., and Fan, J. (2011). Common and distinct networks underlying reward valence and processing stages: a meta-analysis of functional neuroimaging studies. Neurosci. Biobehav. Rev. 35, 1219-1236. doi: 10.1016/j. neubiorev.2010.12.012

Matsumoto, M., and Hikosaka, O. (2009). Two types of dopamine neuron distinctly convey positive and negative motivational signals. Nature 459, 837-841. doi: 10 . 1038/nature08028

Matsumoto, M., Matsumoto, K., Abe, H., and Tanaka, K. (2007). Medial prefrontal cell activity signaling prediction errors of action values. Nat. Neurosci. 10, 647656. doi: 10.1038/nn1890

McClure, S. M., Berns, G. S., and Montague, P. R. (2003). Temporal prediction errors in a passive learning task activate human striatum. Neuron 38, 339-346. doi: 10.1016/s0896-6273(03)00154-5

McCullough, L. D., and Salamone, J. D. (1992). Involvement of nucleus accumbens dopamine in the motor activity induced by periodic food presentation: a microdialysis and behavioral study. Brain Res. 592, 29-36. doi: 10.1016/00068993(92)91654-w

Metereau, E., and Dreher, J. C. (2013). Cerebral correlates of salient prediction error for different rewards and punishments. Cereb. Cortex 23, 477-487. doi: 10. 1093/cercor/bhs037

Monosov, I. E., and Hikosaka, O. (2012). Regionally distinct processing of rewards and punishments by the primate ventromedial prefrontal cortex. J. Neurosci. 32, 10318-10330. doi: 10.1523/jneurosci.1801-12.2012

Montague, P. R., Dayan, P., and Sejnowski, T. J. (1996). A framework for mesencephalic dopamine systems based on predictive Hebbian learning. J. Neurosci. 16, 1936-1947.

Morrison, S. E., Saez, A., Lau, B., and Salzman, C. D. (2011). Different time courses for learning-related changes in amygdala and orbitofrontal cortex. Neuron 71, 1127-1140. doi: 10.1016/j.neuron.2011.07.016

Morrison, S. E., and Salzman, C. D. (2011). Representations of appetitive and aversive information in the primate orbitofrontal cortex. Ann. N Y Acad. Sci. 1239, 59-70. doi: 10.1111/j.1749-6632.2011.06255.x

Nakamura, K., Santos, G. S., Matsuzaki, R., and Nakahara, H. (2012). Differential reward coding in the subdivisions of the primate caudate during an oculomotor task. J. Neurosci. 32, 15963-15982. doi: 10.1523/jneurosci.1518-12. 2012

Newsome, W. T., Glimcher, P. W., Gottlieb, J., Lee, D., and Platt, M. L. (2013). Comment on "In monkeys making value-based decisions, LIP neurons encode cue salience and not action value". Science 340, 430. doi: 10.1126/science. 1233214

Nicola, S. M., Yun, I. A., Wakabayashi, K. T., and Fields, H. L. (2004). Cue-evoked firing of nucleus accumbens neurons encodes motivational significance during a discriminative stimulus task. J. Neurophysiol. 91, 1840-1865. doi: 10.1152/jn. 00657.2003

Niv, Y., and Schoenbaum, G. (2008). Dialogues on prediction errors. Trends Cogn. Sci. 12, 265-272. doi: 10.1016/j.tics.2008.03.006

Niv, Y. (2009). Reinforcement learning in the brain. J. Math. Psychol. 53, 139-154. doi: 10.1016/j.jmp.2008.12.005

Nunes, E. J., Randall, P. A., Podurgiel, S., Correa, M., and Salamone, J. D. (2013). Nucleus accumbens neurotransmission and effort-related choice behavior in food motivation: effects of drugs acting on dopamine, adenosine and muscarinic acetylcholine receptors. Neurosci. Biobehav. Rev. 37, 2015-2025. doi: 10.1016/j. neubiorev.2013.04.002

O'Doherty, J. P. (2004). Reward representations and reward-related learning in the human brain: insights from neuroimaging. Curr. Opin. Neurobiol. 14, 769-776. doi: 10.1016/j.conb.2004.10.016

Oleson, E. B., Gentry, R. N., Chioma, V. C., and Cheer, J. F. (2012). Subsecond dopamine release in the nucleus accumbens predicts conditioned punishment and its successful avoidance. J. Neurosci. 32, 14804-14808. doi: 10. 1523/jneurosci.3087-12.2012

Padoa-Schioppa, C., and Assad, J. A. (2006). Neurons in the orbitofrontal cortex encode economic value. Nature 441, 223-226. doi: 10.1038/nature04676

Padoa-Schioppa, C., and Assad, J. A. (2008). The representation of economic value in the orbitofrontal cortex is invariant for changes of menu. Nat. Neurosci. 11, 95-102. doi: 10.1038/nn2020

Padoa-Schioppa, C. (2011). Neurobiology of economic choice: a good-based model. Annu. Rev. Neurosci. 34, 333-359. doi: 10.1146/annurev-neuro-061010113648
Park, S. Q., Kahnt, T., Rieskamp, J., and Heekeren, H. R. (2011). Neurobiology of value integration: when value impacts valuation. J. Neurosci. 31, 9307-9314. doi: 10.1523/JNEUROSCI.4973-10.2011

Paton, J. J., Belova, M. A., Morrison, S. E., and Salzman, C. D. (2006). The primate amygdala represents the positive and negative value of visual stimuli during learning. Nature 439, 865-870. doi: 10.1038/nature04490

Phelps, E. A., Ling, S., and Carrasco, M. (2006). Emotion facilitates perception and potentiates the perceptual benefits of attention. Psychol. Sci. 17, 292-299. doi: 10. 1111/j.1467-9280.2006.01701.x

Plassmann, H., O’Doherty, J. P., and Rangel, A. (2010). Appetitive and aversive goal values are encoded in the medial orbitofrontal cortex at the time of decision making. J. Neurosci. 30, 10799-10808. doi: 10.1523/jneurosci.0788-10. 2010

Pruessner, J. C., Champagne, F., Meaney, M. J., and Dagher, A. (2004). Dopamine release in response to a psychological stress in humans and its relationship to early life maternal care: a positron emission tomography study using [11C]raclopride. J. Neurosci. 24, 2825-2831. doi: 10.1523/jneurosci.3422-03. 2004

Redish, A. D. (2004). Addiction as a computational process gone awry. Science 306, 1944-1947. doi: 10.1126/science. 1102384

Rescorla, R. A., and Wagner, A. R. (1972). Classical Conditioning II: Current Research and Theory, eds A. Black and W. F. Prokasy (Appleton: Century-Crofts), 64-99.

Roesch, M. R., Calu, D. J., Esber, G. R., and Schoenbaum, G. (2010a). Neural correlates of variations in event processing during learning in basolateral amygdala. J. Neurosci. 30, 2464-2471. doi: 10.1523/jneurosci.5781-09. 2010

Roesch, M. R., Calu, D. J., Esber, G. R., and Schoenbaum, G. (2010b). All that glitters ... dissociating attention and outcome expectancy from prediction errors signals. J. Neurophysiol. 104, 587-595. doi: 10.1152/jn.00173.2010

Roesch, M. R., and Olson, C. R. (2004). Neuronal activity related to reward value and motivation in primate frontal cortex. Science 304, 307-310. doi: 10. 1126/science. 1093223

Rolls, E. T., Sienkiewicz, Z. J., and Yaxley, S. (1989). Hunger modulates the responses to gustatory stimuli of single neurons in the caudolateral orbitofrontal cortex of the macaque monkey. Eur. J. Neurosci. 1, 53-60. doi: 10.1111/j.14609568.1989.tb00774.x

Saddoris, M. P., Gallagher, M., and Schoenbaum, G. (2005). Rapid associative encoding in basolateral amygdala depends on connections with orbitofrontal cortex. Neuron 46, 321-331. doi: 10.1016/j.neuron.2005.02.018

Salamone, J. D. (1986). Different effects of haloperidol and extinction on instrumental behaviours. Psychopharmacology (Berl) 88, 18-23. doi: 10.1007/ bf00310507

Salamone, J. D. (1994). The involvement of nucleus accumbens dopamine in appetitive and aversive motivation. Behav. Brain Res. 61, 117-133. doi: 10 1016/0166-4328(94)90153-8

Salamone, J. D., and Correa, M. (2002). Motivational views of reinforcement: implications for understanding the behavioral functions of nucleus accumbens dopamine. Behav. Brain Res. 137, 3-25. doi: 10.1016/s0166-4328(02)00 282-6

Salamone, J. D., and Correa, M. (2012). The mysterious motivational functions of mesolimbic dopamine. Neuron 76, 470-485. doi: 10.1016/j.neuron.2012.10.021

Salamone, J. D., Correa, M., Nunes, E. J., Randall, P. A., and Pardo, M. (2012). The behavioral pharmacology of effort-related choice behavior: dopamine, adenosine and beyond. J. Exp. Anal. Behav. 97, 125-146. doi: 10.1901/jeab.2012. 97-125

Salamone, J. D., Steinpreis, R. E., McCullough, L. D., Smith, P., Grebel, D., and Mahan, K. (1991). Haloperidol and nucleus accumbens dopamine depletion suppress lever pressing for food but increase free food consumption in a novel food choice procedure. Psychopharmacology (Berl) 104, 515-521. doi: 10. 1007/bf02245659

Schoenbaum, G., Chiba, A. A., and Gallagher, M. (1998). Orbitofrontal cortex and basolateral amygdala encode expected outcomes during learning. Nat. Neurosci. 1, 155-159. doi: 10.1038/407

Schoenbaum, G., Chiba, A. A., and Gallagher, M. (1999). Neural encoding in orbitofrontal cortex and basolateral amygdala during olfactory discrimination learning. J. Neurosci. 19, 1876-1884.

Schoenbaum, G., and Roesch, M. (2005). Orbitofrontal cortex, associative learning, and expectancies. Neuron 47, 633-636. doi: 10.1016/j.neuron.2005.07.018 
Schoenbaum, G., Setlow, B., Nugent, S. L., Saddoris, M. P., and Gallagher, M. (2003a). Lesions of orbitofrontal cortex and basolateral amygdala complex disrupt acquisition of odor-guided discriminations and reversals. Learn. Mem. 10, 129-140. doi: 10.1101/lm.55203

Schoenbaum, G., Setlow, B., Saddoris, M. P., and Gallagher, M. (2003b). Encoding predicted outcome and acquired value in orbitofrontal cortex during cue sampling depends upon input from basolateral amygdala. Neuron 39, 855-867. doi: 10.1016/s0896-6273(03)00474-4

Schultz, W. (1997). Dopamine neurons and their role in reward mechanisms. Curr. Opin. Neurobiol. 7, 191-197. doi: 10.1016/s0959-4388(97)80007-4

Schultz, W. (1998). Predictive reward signal of dopamine neurons. J. Neurophysiol. 80, 1-27.

Schultz, W., Apicella, P., Scarnati, E., and Ljungberg, T. (1992). Neuronal activity in monkey ventral striatum related to the expectation of reward. J. Neurosci. 12, 4595-4610.

Schultz, W., Tremblay, L., and Hollerman, J. R. (2000). Reward processing in primate orbitofrontal cortex and basal ganglia. Cereb. Cortex 10, 272-284. doi: 10.1093/cercor/10.3.272

Setlow, B., Schoenbaum, G., and Gallagher, M. (2003). Neural encoding in ventral striatum during olfactory discrimination learning. Neuron 38, 625-636. doi: 10. 1016/s0896-6273(03)00264-2

Shabel, S. J., and Janak, P. H. (2009). Substantial similarity in amygdala neuronal activity during conditioned appetitive and aversive emotional arousal. Proc. Natl. Acad. Sci. U S A 106, 15031-15036. doi: 10.1073/pnas.0905580106

Shidara, M., and Richmond, B. J. (2004). Differential encoding of information about progress through multi-trial reward schedules by three groups of ventral striatal neurons. Neurosci. Res. 49, 307-314. doi: 10.1016/j.neures.2004.03.008

Singh, T., McDannald, M. A., Haney, R. Z., Cerri, D. H., and Schoenbaum, G. (2010). Nucleus accumbens core and shell are necessary for reinforcer devaluation effects on pavlovian conditioned responding. Front. Integr. Neurosci. 4:126. doi: 10.3389/fnint.2010.00126

Small, D. M., Gregory, M. D., Mak, Y. E., Gitelman, D., Mesulam, M. M., and Parrish, T. (2003). Dissociation of neural representation of intensity and affective valuation in human gustation. Neuron 39, 701-711. doi: 10.1016/s08966273(03)00467-7

Solomon, R. L., and Corbit, J. D. (1974). An opponent-process theory of motivation. I. Temporal dynamics of affect. Psychol. Rev. 81, 119-145. doi: 10. 1037/h0036128

Stalnaker, T. A., Roesch, M. R., Franz, T. M., Calu, D. J., Singh, T., and Schoenbaum, G. (2007). Cocaine-induced decision-making deficits are mediated by miscoding in basolateral amygdala. Nat. Neurosci. 10, 949-951. doi: 10.1038/nn1931

Stalnaker, T. A., Takahashi, Y., Roesch, M. R., and Schoenbaum, G. (2009). Neural substrates of cognitive inflexibility after chronic cocaine exposure. Neuropharmacology 56(Suppl. 1), 63-72. doi: 10.1016/j.neuropharm.2008.07.019

Stopper, C. M., and Floresco, S. B. (2011). Contributions of the nucleus accumbens and its subregions to different aspects of risk-based decision making. Cogn. Affect. Behav. Neurosci. 11, 97-112. doi: 10.3758/s13415-010-0015-9

Sutton RaB, AG. editor (1998). Reinforcement Learning: An Introduction. MA Cambridge: MIT Press.

Takahashi, Y. K., Roesch, M. R., Wilson, R. C., Toreson, K., O’Donnell, P., Niv, Y., et al. (2011). Expectancy-related changes in firing of dopamine neurons depend on orbitofrontal cortex. Nat. Neurosci. 14, 1590-1597. doi: 10.1038/nn. 2957

Takahashi, Y., Schoenbaum, G., and Niv, Y. (2008). Silencing the critics: understanding the effects of cocaine sensitization on dorsolateral and ventral striatum in the context of an actor/critic model. Front. Neurosci. 2, 86-99. doi: 10. 3389/neuro.01.014.2008

Talmi, D., Dayan, P., Kiebel, S. J., Frith, C. D., and Dolan, R. J. (2009). How humans integrate the prospects of pain and reward during choice. J. Neurosci. 29, 1461714626. doi: 10.1523/jneurosci.2026-09.2009
Tricomi, E. M., Delgado, M. R., and Fiez, J. A. (2004). Modulation of caudate activity by action contingency. Neuron 41, 281-292. doi: 10.1016/s08966273(03)00848-1

Tye, K. M., Cone, J. J., Schairer, W. W., and Janak, P. H. (2010). Amygdala neural encoding of the absence of reward during extinction. J. Neurosci. 30, 116-125. doi: 10.1523/jneurosci.4240-09.2010

Tye, K. M., and Janak, P. H. (2007). Amygdala neurons differentially encode motivation and reinforcement. J. Neurosci. 27, 3937-3945. doi: 10.1523/jneurosci. 5281-06.2007

Ungless, M. A., Magill, P. J., and Bolam, J. P. (2004). Uniform inhibition of dopamine neurons in the ventral tegmental area by aversive stimuli. Science 303, 2040-2042. doi: 10.1126/science.1093360

van der Meer, M. A., Johnson, A., Schmitzer-Torbert, N. C., and Redish, A. D. (2010). Triple dissociation of information processing in dorsal striatum, ventral striatum and hippocampus on a learned spatial decision task. Neuron 67, 25-32. doi: 10.1016/j.neuron.2010.06.023

van der Meer, M. A., and Redish, A. D. (2009). Covert expectation-of-reward in rat ventral striatum at decision points. Front. Integr. Neurosci. 3:1. doi: 10. 3389/neuro.07.001.2009

van der Meer, M. A., and Redish, A. D. (2011). Ventral striatum: a critical look at models of learning and evaluation. Curr. Opin. Neurobiol. 21, 387-392. doi: 10. 1016/j.conb.2011.02.011

Wadenberg, M. L., Ericson, E., Magnusson, O., and Ahlenius, S. (1990). Suppression of conditioned avoidance behavior by the local application of (-)sulpiride into the ventral, but not the dorsal, striatum of the rat. Biol. Psychiatry 28, $297-$ 307. doi: 10.1016/0006-3223(90)90657-n

Wakabayashi, K. T., Fields, H. L., and Nicola, S. M. (2004). Dissociation of the role of nucleus accumbens dopamine in responding to reward-predictive cues and waiting for reward. Behav. Brain Res. 154, 19-30. doi: 10.1016/j.bbr.2004. 01.013

Wallis, J. D., and Miller, E. K. (2003). Neuronal activity in primate dorsolateral and orbital prefrontal cortex during performance of a reward preference task. Eur. J. Neurosci. 18, 2069-2081. doi: 10.1046/j.1460-9568.2003.02 922.x

Winston, J. S., Gottfried, J. A., Kilner, J. M., and Dolan, R. J. (2005). Integrated neural representations of odor intensity and affective valence in human amygdala. J. Neurosci. 25, 8903-8907. doi: 10.1523/jneurosci.1569-05. 2005

Yun, I. A., Wakabayashi, K. T., Fields, H. L., and Nicola, S. M. (2004). The ventral tegmental area is required for the behavioral and nucleus accumbens neuronal firing responses to incentive cues. J. Neurosci. 24, 2923-2933. doi: 10. 1523/jneurosci.5282-03.2004

Conflict of Interest Statement: The authors declare that the research was conducted in the absence of any commercial or financial relationships that could be construed as a potential conflict of interest.

Received: 29 October 2013; accepted: 04 February 2014; published online: 04 March 2014.

Citation: Bissonette GB, Gentry RN, Padmala S, Pessoa L and Roesch MR (2014) Impact of appetitive and aversive outcomes on brain responses: linking the animal and human literatures. Front. Syst. Neurosci. 8:24. doi: 10.3389/fnsys.2014.00024

This article was submitted to the journal Frontiers in Systems Neuroscience.

Copyright (c) 2014 Bissonette, Gentry, Padmala, Pessoa and Roesch. This is an openaccess article distributed under the terms of the Creative Commons Attribution License (CC BY). The use, distribution or reproduction in other forums is permitted, provided the original author(s) or licensor are credited and that the original publication in this journal is cited, in accordance with accepted academic practice. No use, distribution or reproduction is permitted which does not comply with these terms. 